\title{
Elementos da teoria semiótica da percepção de Peirce para o desenvolvimento de interfaces de recuperação da informação
}

\author{
Elementos de la teoría semiótica de la percepción de Peirce \\ para el desarrollo de interfaces de recuperación de información
}

Elements of Peirce's semiotic theory of perception for the development of information retrieval interfaces

Fabricio Baptista (1), Carlos Cândido de Almeida (2), Edberto Ferneda (2)

\begin{abstract}
Instituto Federal do Paraná, Campus Jacarezinho, Avda. Dr. Tito, s/n, PR, (Brasil), fabriciobri@gmail.com
(2) Departamento de Ciência da Informação, Universidade Estadual Paulista, Av. Hygino Muzzi Filho, 737, Marília, SP (Brasil), carlosalmeida@marilia.unesp.br, ferneda@marilia.unesp.br
\end{abstract}

\begin{abstract}
Resumen
Se exploran los conceptos básicos de la percepción en Charles Sanders Peirce relacionándolos con los procesos perceptivos que afectan al diseño de interfaces digitales en el campo de la recuperación de información. Se pretenden dar a conocer las bases conceptuales de la semiótica peirceana, junto a otras teorías relacionadas con el proceso perceptivo, como bases teóricas de una Ingeniería Semiótica. Los resultados de la investigación indican que es adecuado considerar los elementos del proceso de percepción recogidos por Peirce y los tipos de mediación (icónica, indicial y simbólica) en la interacción hombre-ordenador. Sintéticamente, se puede observar que la formación del pensamiento comienza por las puertas de la percepción, haciendo relevante su estudio para el desarrollo de interfaces de ordenador, especialmente en el ámbito de la recuperación de información.
\end{abstract}

Palabras clave: Percepción. Teoría de la percepción. Peirce, Charles Sanders. Interfaces de recuperación de información. Semiótica.

\section{Introdução}

Uma das formas de se introduzir um tema é a partir de uma definição, porém a palavra percepção, conforme discorreremos durante este artigo, não se refere a um evento isolado. Existem diversas teorias que abordam o tema, como a Empirista, a Intelectualista, a Psicologia da forma (ou teoria da Gestalt) e a Fenomenologia, em que a percepção é descrita através de um processo integrado, e pode ser considerada fundamental para compreender o conhecimento humano. Desta forma, entende-se que a percepção é " a ponte entre o mundo da linguagem - a consciência, o cérebro, a mente - e o mundo lá fora" (Santaella, 2012b, p. 75).

Neste sentido, alguns aspectos da percepção estão relacionados à organização do conhecimento. Para Barros e Café (2012) os processos

\begin{abstract}
This article explores the basic concepts of perception in Charles Sanders Peirce relating them to perceptual processes that affect the design of digital interfaces in the field of information retrieval. For this, it was tried to present the conceptual bases of peircean semiotics, along with other theories related to the perceptive process, as theoretical bases of a Semiotic Engineering. The results of the research indicate that it is appropriate to consider the elements of the process of perception collected by Peirce and the types of mediation (iconic, indicial and symbolic) in the human-computer interaction. Synthesizing, it can be observed that the formation of the thought begins at the doors of perception, making relevant its study for the development of computer interfaces, especially in the scope of information retrieval.
\end{abstract}

Keywords: Perception. Theory of perception. Information retrieval interfaces. Semiotics. Peirce, Charles Sanders.

de significação são importantes aspectos da Ciência da Informação $(\mathrm{Cl})$ no que diz respeito à organização e representação do conhecimento, uma vez que a $\mathrm{Cl}$ desenvolve métodos para interpretar diferentes constituições textuais. Para as autoras esse processo de significação também é vislumbrado pela Semiótica, ciência dos signos produzidos nos âmbitos da natureza e da cultura (Santaella, 1983 apud Nöth, 2003). O processo de percepção pode ser explicado pela arquitetura filosófica de Charles Sanders Peirce (1839-1914). Assim, surgiu a seguinte questão teórica, quais aspectos da semiótica peirceana contribuem para compreensão do processo de percepção humana? Em consequência, quais elementos são importantes para a recuperação da informação ensejada pela Ciência da Informação? Nesse sentido, trabalhou-se com base em dois argumentos. Presume-se que a semiótica peirceana explica o processo perceptivo com desenvolvimento de interfaces de recuperação da informação. // Scire. 23:2 (jul.-dic. 2017) 53-62. ISSN 1135-3716. 
base em uma rede de semiose, contribuindo para o entendimento do processo de percepção. Além disso, outro ponto,é que os fenômenos se apresentam por meio de signos que são percebidos e interpretados, e podem influenciar o processo de percepção no instante da recuperação da informação.

Para dar suporte a essas argumentações delineou-se alguns objetivos que nortearam a estruturação deste trabalho. Como objetivo geral, apresenta-se uma revisão conceitual dos elementos da teoria da percepção segundo a semiótica peirceana que podem contribuir para o entendimento dos fatores intervenientes da recuperação da informação em interfaces digitais. No que tange aos objetivos específicos, procura-se contextualizar a teoria da percepção de Peirce junto a outras teorias que envolvem a percepção, além de examinar as aplicações dessas teorias na área da Ciência da Informação. Conforme explica Santaella (2012b), o entendimento da teoria da percepção de Peirce está intimamente ligada aos conceitos da sua arquitetura filosófica.

\section{Semiótica Peirceana}

As bases conceituais na elaboração deste trabaIho foram a fenomenologia e a semiótica peirceana. Com isso, faz-se essencial a introdução desses temas, ainda que sucinta, para o desenvolvimento do assunto. Dentre os diversos conceitos que compõem essas áreas, objetiva-se realçar os elementos que servem como base para a teoria da percepção de Peirce.

Diferentes autores exploram a semiótica sob diferentes perspectivas. Em a "Semiótica do Século XX", Nöth (1996) abordou alguns desses teóricos, como: Saussure, Hjelmslev, Jakobson, Barthes, Eco, entre outros. Embora não tenha abordado Peirce junto aos teóricos do século $X X$, ele reconhece a importância dos paradigmas peirceanos, os quais foram tratados em uma obra anterior do autor. Apesar de existirem diversas abordagens, limita-se à definição de semiótica empregada por Santaella (1983 apud NÖTH, 2003 , p. 17), que se alinha com o pensamento peirceano. Neste ponto de vista, a "semiótica é a ciência dos signos e dos processos significativos (semiose) na natureza e na cultura".

$\mathrm{Na}$ arquitetura filosófica de Charles Sanders Peirce há um caminho importante que liga a fenomenologia ao pragmatismo, percorrendo as ciências estética, ética, lógica ou semiótica e metafísica. Conforme descrito por Santaella (2012a), apesar da fenomenologia se desenvolver independente, ela serviu como alicerce para as ciências normativas. Na visão da autora a preocupação fenomenológica constitui-se na base de toda filosofia de
Peirce. A fenomenologia teria como objetivo postular formas e propriedades universais observando os fenômenos em qualquer área da ciência, a palavra fenômeno deriva de phaneron, ou seja, qualquer coisa que aparece de qualquer modo à mente, sendo que, na concepção de Peirce, os fenômenos não possuem nenhuma moldura preestabelecida, e ainda (Santaella, 1995, p. 16):

Fenômeno é qualquer coisa que aparece à mente, seja ela meramente sonhada, imaginada, concebida, vislumbrada, alucinada... Um devaneio, um cheiro, uma ideia geral e abstrata da ciência... Enfim, qualquer coisa.

Nöth (2003, p. 63-64) explicou que na busca por definir categorias que servissem de modelo para conter a multiplicidade de fenômenos do mundo, Peirce desenvolveu uma fenomenologia recorrendo a três categorias, as quais denominou Firsthess, Secondness e Thirdness, que podem traduzidas por primeiridade, secundidade e terceiridade:

Primeiridade é a categoria das coisas, sem nenhuma relação com outros fenômenos do mundo [...]. Secundidade começa quando um fenômeno primeiro é relacionado a um segundo fenômeno qualquer [...]. Terceiridade é a categoria que relaciona um fenômeno segundo a um terceiro [...]. A base do signo é, portanto uma relação triádica desses três elementos.

Reforçando esta visão, "Primeiridade é o começo, aquilo que tem frescor, é original, espontâneo, livre. Secundidade é aquilo que é determinado, terminado, final, correlativo, objeto, necessitado, reativo. Terceiridade é o meio, devir, desenvolvimento" (Santaella, 2012b, p.79).

A noção de signo corresponde à terceira das categorias fenomenológicas. Peirce (2005, p. 46) sintetiza que

[...] um signo, ou representâmen, é aquilo que, sob certo aspecto ou modo, representa algo para alguém. [...] Ao signo assim criado denomino interpretante do primeiro signo. O signo representa alguma coisa, seu objeto.

Além das categorias fundamentais de Peirce e da noção de signo, outro elemento relevante ao estudo da percepção é a concepção de objeto (objeto dinâmico e imediato). Nöth (2003, p.67) fundamenta o conceito de objeto na obra de Peirce, salientando que ele pode ser "uma coisa material do mundo", do qual temos um "conhecimento perceptivo", mas também pode ser entidade meramente mental ou imaginária. Além disso, Peirce descreveu dois tipos de objeto: objeto dinâmico e objeto imediato. Santaella (2015, p. 34) esclarece que objeto imediato denota um objeto dinâmico e, portanto: 
[...] o melhor caminho para começar a análise da relação objetal é o do objeto imediato. Afinal, parece não haver outro modo de começar, visto que o objeto dinâmico só se faz presente, mediatamente, via objeto imediato, este interno ao signo.

A divisão dos objetos do signo em dinâmico e imediato mostra que, com o objeto dinâmico, Peirce (1994, CP 5.212) identificou aquilo que está fora da cadeia sígnica, aquilo que algumas vezes ele chamou de "real" ou "realidade", mas que pode ser também fictício. Esse esclarecimento será importante para a elucidação dos conceitos de percepto e percipuum, os quais serão abordados adiante.

Nöth (2003, p.76) explica que "Peirce desenvolveu uma tipologia elaborada de signos com base em uma classificação do representâmen, objeto e interpretante, cada uma em três classes denominadas tricotomias". Almeida (2009, p.246) destaca as três tricotomias do signo mais desenvolvidas:

A primeira tricotomia trata da relação do signo com ele mesmo; a segunda tricotomia propõe signos resultantes da relação do signo com o objeto; e por fim, a terceira tricotomia especifica os signos produzidos no seio da conexão signo e interpretante.

Sabendo-se que o termo tricotomia se refere à divisão dos elementos em três partes, cada uma das tricotomias listadas possuem termos para designar esses elementos, os quais são relacionados às categorias universais (primeiridade, secundidade e terceiridade). Mesmo reconhecendo a importância das três tricotomias, especificamente neste artigo, será evidenciada a segunda tricotomia (relação do signo com o objeto), a qual servirá como apoio à reflexão sobre percepção. Outro fator importante, destacado por Nöth (2003, p. 78), é que Peirce considera a segunda tricotomia como "a divisão mais importante dos signos". Os elementos que compõem esta divisão são o ícone, o índice e o símbolo. A seguir remete-se a definição de Peirce (2005, p. 73):

Uma progressão regular de um, dois, três pode ser observada nas três ordens de signos, Ícone, Índice e Símbolo. O Ícone não tem conexão dinâmica alguma com o objeto que representa; simplesmente acontece que suas qualidades se assemelham às do objeto e excitam sensações análogas na mente para a qual é uma semelhança. Mas, na verdade, não mantém conexão com elas. O Índice está fisicamente conectado com seu objeto; formam, ambos, um par orgânico, porém a mente interpretante nada tem a ver com essa conexão, exceto o fato de registrá-la, depois de ser estabelecida. O Símbolo está conectado ao seu objeto por força da ideia da mente-que-usa-o-símbolo, sem a qual essa conexão não existiria.

Nesse sentido, por ícone entende-se que ele representa algo através de uma relação de analo- gia, ou seja, apresenta características que se assemelham com o objeto. Exemplificando, em interfaces digitais de recuperação de informação usualmente utiliza-se imagens como por exemplo a de um teclado de computador para representação do próprio objeto, entretanto ressaltase que as semelhanças não são necessariamente visuais, um som ou um perfume poderiam ser ícones em potencial. Já o índice, por sua vez, é um indicador de um objeto, é um signo que através de indícios (causa) remete ao que está sendo representado induzindo uma reação a quem o vê. Por fim, o símbolo apresenta uma relação de convenção com o objeto que representa, geralmente é estabelecido de forma arbitrária, como por exemplo uma palavra utilizada para representar um objeto qualquer.

Neste momento é pertinente salientar que a progressividade de atuação dos três elementos (ícone, índice e símbolo) dá suporte a perspectivas no que diz respeito à análise do julgamento perceptivo (terceiro elemento do modelo triádico), entretanto esta relação será apresentada nas próximas seções.

O último componente da arquitetura filosófica de Peirce a ser abordado é a lógica crítica, que também faz relação com o julgamento perceptivo através das inferência abdutivas que são derivadas do conceito de abdução. Antes de Peirce, somente a indução e a dedução eram consideradas tipos ou métodos de raciocínio, ele criou o termo abdução. Peirce classificou esses tipos dentro de suas categorias universais, onde a abdução estaria para a primeiridade, como a indução para a secundidade e a dedução em nível de terceiridade. Ibri (2006, p.93) utiliza o próprio Peirce para explicar "a abdução como o processo para formar hipóteses explicativas. É a única operação lógica a introduzir ideias novas; pois que a indução não faz mais que determinar um valor, e a dedução envolve apenas as consequências necessárias de uma pura hipótese" (Peirce, 1994, CP 5.171, p. 1736).

A semiótica peirceana evidencia alguns elementos essenciais da teoria da percepção. A seguir será exposta a teoria da percepção de Peirce e as possíveis relações com o desenvolvimento de interfaces digitais.

\section{Teoria da percepção em Peirce e as contribuições para o desenvolvimento de interfaces Web}

O objetivo inicial desta seção é apresentar os tópicos centrais da teoria da percepção em Peirce. Em um segundo momento, será relacionada a abordagem da percepção em Peirce com o desenvolvimento de interfaces Web. Contudo, inicia-se 
por tratar o assunto de maneira geral. As pesquisas sobre percepção têm colaborado para ampliar a compreensão de cognição, no sentido de analisar como se realiza o fenômeno "conhecer". Santaella (2012b, p. 1) inicia sua obra sobre percepção, enfatizando o crescente interesse sobre o tema, sobretudo a partir do século XIX, com o impulso das ciências cognitivas. Essas pesquisas estão inseridas em diferentes abordagens que permeiam as diversas áreas de conhecimento.

A maioria das pesquisas sobre percepção apresentou alguma ligação com o sistema visual humano, tais como: percepção visual, visualização de informação e ensino (Correia, 2001; Loomis, 2003; Santos, 2003; Alexandre e Tavares, 2007; Sousa, 2009; Andrade et al., 2012; Jorge; Rezende e Wartha, 2013; Matsunaga, 2015).

Também depara-se com pesquisas que apresentam análises individuais das teorias da percepção de Peirce, Merleau-Ponty e Gödel (Frankenthal, 2004; Nobrega, 2008; Schultz, 2012). Rego, Pessoa e Gala (2015) discutiram as diferenças da teoria da percepção de Bertand Russell, Charles Sanders Peirce e Alberto Caeiro. Moraes, Pereira e Pantaleão (2012) analisaram as correlações da teoria peirceana para a abordagem ecológica através da aproximação entre as perspectivas ecológica e pragmatista para verificar em que medida o pragmatismo peirceano contribuiria para o estudo da percepção. Os autores relataram que a partir dos pressupostos do realismo direto, percepção direta (em certo grau) e abordagem sistêmica é possível a aproximação entre as abordagens classificando como um novo campo conceitual para a compreensão da percepção segundo a perspectiva direta. A única ressalva é quanto ao julgamento perceptivo (elemento essencial à percepção, segundo Peirce) , pois "extrapola o escopo da abordagem ecológica, uma vez que engloba regras e hábitos, que podem ser simultâneos à percepção, que não são explicitados pela abordagem ecológica" (Moraes, Pereira e Pantaleão, 2012, p. 203).

Algumas produções científicas exemplificaram a aplicação da teoria da percepção de Peirce em espaços geográficos (Rocha, 2002; Mucelin e Bellini, 2008). Enfim, estes exemplos proporcionam uma visão mais ampla sobre o conceito de percepção e seus potenciais de aplicação. Além disso, ratificaram a importância dos comentadores e teóricos da semiótica e da percepção.

Nos diversos temas apresentados, invariavelmente, surgiram questões como: "O que é percepção?", e "Qual o significado de percepção?" uma das primeiras ideias seria a busca do termo em um dicionário da língua. Entretanto, quando se realiza um estudo um pouco mais minucioso, é possível constatar que este tipo de significação é bem restrito, já que sua definição possui diferentes conceitos, a depender da abordagem teórica. As abordagens sobre percepção envolvem uma variedade de compreensões, que nem sempre dirigem-se para um consenso. A seguir, será apresentado um panorama dessas abordagens.

Para prosseguir com a inquirição sobre o conceito de percepção é importante confrontá-lo ao conceito de sensação, as teorias que discutem essa relação são apresentadas no Quadro 1.

\begin{tabular}{|c|c|}
\hline Teorias & Concepções \\
\hline Empirista & $\begin{array}{l}\text { A sensação e a percepção dependem das coisas exteriores; } \\
\text { A sensação seria pontual, isto é, um ponto do objeto externo toca um de meus órgãos dos sentidos e faz um } \\
\text { percurso no interior do meu corpo, indo ao cérebro e voltando às extremidades sensoriais; } \\
\text { Cada sensação é independente das outras e cabe à percepção unificá-las e organizá-las numa síntese; } \\
\text { A causa do conhecimento sensível é a coisa externa, de modo que a sensação e a percepção são efeitos } \\
\text { passivos de uma atividade dos corpos exteriores sobre o nosso corpo; } \\
\text { O conhecimento é obtido por soma e associação das sensaçães na percepção e tal soma e associação } \\
\text { dependem da frequência, da repetição e da sucessão dos estímulos externos e de nossos hábitos }\end{array}$ \\
\hline Intelectualista & $\begin{array}{l}\text { A sensação e a percepção dependem do sujeito do conhecimento e a coisa exterior é apenas a ocasião para } \\
\text { que tenhamos a sensação ou a percepção; } \\
\text { Sentir e perceber são fenômenos que dependem da capacidade do sujeito para decompor um objeto em suas } \\
\text { qualidades simples (a sensação) e de recompor o objeto como um todo, dando-lhe organização e } \\
\text { interpretação (a percepção); } \\
\text { A passagem da sensação para a percepção é, neste caso, um ato realizado pelo intelecto do sujeito do } \\
\text { conhecimento, que confere organização e sentido às sensações; } \\
\text { Não haveria algo propriamente chamado percepção, mas sensações dispersas ou elementares; sua } \\
\text { organização ou síntese seria feita pela inteligência e receberia o nome de percepção }\end{array}$ \\
\hline $\begin{array}{l}\text { Psicologia } \\
\text { da forma } \\
\text { e } \\
\text { fenomenologia }\end{array}$ & $\begin{array}{l}\text { Contra o empirismo, que a sensação não é reflexo pontual ou uma resposta físico-fisiológica a um estímulo } \\
\text { externo também pontual; } \\
\text { Contra o intelectualismo, que a percepção não é uma atividade sintética feita pelo pensamento sobre as } \\
\text { sensações; } \\
\text { Contra o empirismo e o intelectualismo, que não há diferença entre sensação e percepção. }\end{array}$ \\
\hline
\end{tabular}

Quadro I. Teorias sobre sensação e percepção.

Elaborado pelo autor baseado em Chauí (2000, p. 151-153) 
A partir dessas informações, Chauí (2000, p. 153) conclui que, para os empiristas e intelectualistas, a percepção era considerada a atividade que unia as partes numa síntese que seria o objeto percebido. Na psicologia da forma e na fenomenologia a autora salienta que:

[...] não há diferença entre sensação e percepção porque nunca temos sensações parciais, pontuais ou elementares, isto é, sensações separadas de cada qualidade, que depois o espírito juntaria e organizaria como percepção de um único objeto. Sentimos e percebemos formas, isto é, totalidades estruturadas dotadas de sentido ou de significação.

Pode-se constatar que existem várias abordagens em relação a sensação e percepção, mas independentemente da perspectiva, são temas relacionados e, por muitas vezes, estudados em conjunto. A seguir, apresentam-se as abordagens de Merleau-Ponty e Gibson.

Merleau-Ponty, em sua teoria da Fenomenologia da Percepção, apresenta uma análise da percepção por meio da revisão do conceito de sensação, Santaella (2012b) observa que para Merleau-Ponty deve ser rejeitada qualquer tentativa de decomposição da percepção em sensações. Seguindo a mesma linha, na teoria de Gestalt a mente humana configura as informações através dos canais sensoriais, percepção e/ou da memória (pensamento, cognição e resolução de problemas). Na experiência humana do meio ambiente, esta configuração tem um caráter primário sobre os elementos que o compõem, e assim a soma desses elementos por si só não poderia levar-nos à compreensão do todo.

Neste panorama, das teorias que versam sobre percepção, é importante citar "A Ecologia da Percepção", cujo fundador foi James J. Gibson. Seria inviável sintetizá-la neste estudo, entretanto podemos elencar algumas contribuições importantes. Para Santaella (2012b) destacam-se algumas características: designação do conceito de Affordance: tudo aquilo que o ambiente oferece ao observador; esta teoria sofreu influência da teoria da Gestalt, mas também a refutou; as teses gibsonianas mais refutadas e submetidas a discussões são a percepção direta (sem a mediação de representações mentais internas) e imediata e a da negação de qualquer papel desempenhado pela mente na percepção.

Completando este cenário das teorias, posiciona-se aqui a Teoria da Percepção de Peirce, a qual é um dos objetos deste trabalho.

\subsection{O processo de percepção em Peirce}

Pretende-se abordar, neste tópico, as conexões entre a semiótica peirceana e o contexto em que essa teoria se desenvolveu, com o objetivo de fornecer uma visão clara daquele que é o tema central deste trabalho. Algumas dessas conexões já foram descritas ao longo do trabalho, mas reaparecem aqui de forma mais ordenada.

De acordo com Santaella (2012b, p.89), foram poucos estudiosos da obra peirceana que se empenharam a investigar seus escritos sobre percepção. Ela realizou uma análise dos comentadores de Peirce que se dedicaram ao tema, e também aos ensaios peirceanos publicados. Como consequência desta exploração, destacaram-se diversos elementos importantes, os quais serviram de suporte ao desenvolvimento deste assunto.

No livro, A percepção: uma teoria semiótica, Santaella $(1998$, p. 16) afirma que, "em termos lógicos, ontológicos e epistemológicos”, nenhuma outra teoria sobre percepção é tão completa quanto a peirceana, fundamentando-se em dois argumentos apresentados por Peirce: 1) "não há, nem pode haver, separação entre percepção e conhecimento"; 2 ) "todo pensamento lógico, toda cognição, entre pela porta da percepção e sai pela porta da ação deliberada."

Nessa perspectiva, as afirmações atestam a relevância do processo perceptivo na construção do conhecimento, sendo a percepção o elo entre a mente e o mundo exterior. Com o objetivo de esclarecer a composição da teoria da percepção, apresenta-se a seguir o modelo triádico formulado por Peirce, o qual está intimamente conectado aos conceitos já apresentados.

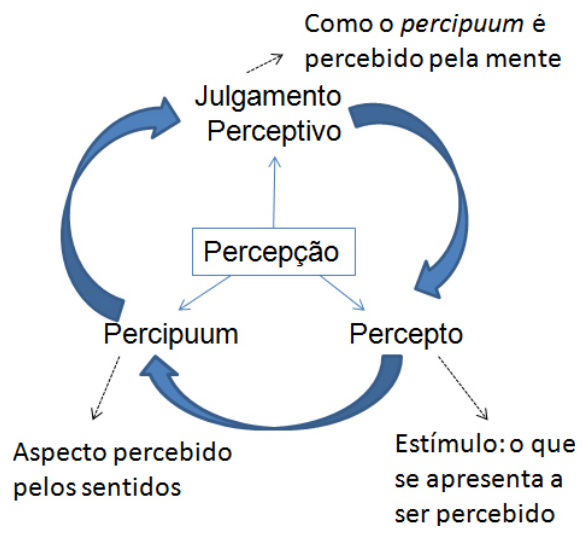

Figura 1. Constituintes peirceanos da percepção. Elaborado pelo autor baseado em Mucelin e Bellini (2008, p.124)

Ao iniciar a explanação sobre o modelo triádico da percepção peirceana é importante salientar que os elementos a serem descritos a seguir são associados aos conceitos iniciais do seu projeto filosófico. Na explicação de Santaella (2012b, p. 75), a percepção desempenha o papel de ponte entre o mundo da linguagem - a consciência, o cérebro, 
a mente - e o mundo lá fora. A percepção é, para Peirce, o objeto de estudo da semiótica que ocorre segundo um modelo triádico e está constituído de: Percepto, Percipuum e Julgamento Perceptivo. A autora salienta que Peirce produziu a única teoria triádica da percepção, e explica que a percepção está sob a dominância da secundidade. A figura 1 procura mostrar a relação entre os elementos peirceanos da percepção.

A partir da proposta triádica ilustrada pela figura 1, Mucelin e Bellini (2008, p.125) consideram os constituintes da percepção como "entes interdependentes e indecomponíveis que permitem que se analise e caracterize isoladamente cada um deles". Explica-se esses elementos da seguinte forma: percepto ou objeto, verdadeira coisa em si mesma, que independe daquilo que dele se possa pensar, devido à sua existência e insistência sobre os sentidos sem nada manifestar; o percipuum ou o modo como o percepto, captado pelos órgãos sensoriais, é imediatamente interpretado no julgamento de percepção; e o julgamento perceptivo, que corresponde a uma espécie de proposição a nos informar sobre aquilo que está sendo percebido. Ainda sobre essa relação triádica, deve-se destacar uma passagem do próprio Peirce (, 1994, p. 39, CP 7.643):

Não sabemos nada sobre o percepto a não ser pelo testemunho do juízo perceptual, exceto que sentimos o seu golpe, a reação dele contra nós, e vemos os conteúdos dele arranjados num objeto, na sua totalidade - excetuando-se também, é claro, o que os psicólogos são capazes de extrair inferencialmente. Mas, no momento em que fixamos nossa mente sobre ele e pensamos a menor coisa sobre $o$ percepto, é o juízo perceptual que nos diz o que nós assim 'percebemos'. Por esta e outras razões, proponho considerar o percepto tal como ele é imediatamente interpretado no juízo perceptual, sob o nome de percipuum.

Peirce nos apresenta neste trecho a indissociabilidade dos elementos no processo perceptual. Nesta concepção considera-se o percipuum a imediata interpretação do percepto através do juízo perceptual , ou seja, o percipuum apresentase como um elemento derivado do próprio percepto que já é resultado de uma elaboração mental que utiliza-se da organização que regulam os nossos julgamentos. Santaella (2012b, p. 95) também discorre sobre a tríade perceptiva, da seguinte maneira:

A percepção é determinada pelo percepto, mas este só pode ser conhecido através da mediação do signo, que é o julgamento da percepção. Para que esse conhecimento se dê, o percepto deve, de algum modo, estar representado no signo. Aquilo que representa o percepto, dentro do julgamento per- ceptivo, é o percipuum, meio mental de ligação entre o que está fora e o juízo perceptivo, que já é fruto de uma elaboração mental.

Hausman (2006, p. 242) comenta que Peirce discute a função do percepto no início do processo de interpretação. Nesta visão, são sugeridos dois novos elementos o "antecepto" e o "ponecepto". Um percepto isolado é apenas uma possibilidade perceptiva. O percepto sempre ocorre em sequências seriais que envolvem memórias recentes e antecipações futuras, chamadas respectivamente de poneceptos e anteceptos. Romanini (2006, p.68) complementa:

Perceptos similares chegam e coalescem na mente para formar o universo perceptivo, uma espécie de imagem mental, uma "ideia" que é o ground do julgamento perceptivo. Essa ideia é uma metáfora. O percipuum, portanto, é o percepto representado no julgamento perceptivo. É uma ficção, uma hipótese, assim como também o são o ponecipuum e o antecipuum.

De acordo com Santaella (2012b), ao analisar a teoria peirceana da percepção, no âmbito da semiótica, o percepto funciona como objeto dinâmico enquanto o percipuum seria o objeto imediato. Nesta mesma análise é possível incluir o terceiro elemento da tríade, o julgamento de percepção. Santaella(2012b) referencia a obra de $\mathrm{R}$. Bernstein (1964), em que o julgamento de percepção é correlacionado com as inferências abdutivas sendo o elemento que desempenha o papel cognitivo na percepção. Nesse aspecto, a autora exemplifica afirmando que "são os juízos perceptivos que nos dizem, por exemplo, que o cheiro que estamos sentindo é de brócolis cozido, que aquilo que estamos vendo é uma lua cheia solitariamente iluminando o céu" (Santaella, 2012b, p.95).

A tríade da percepção permite vislumbrar análises de diferentes situações do cotidiano. Para reforçar o entendimento pode-se exemplificar através da seguinte situação: um indivíduo observa um obra de arte. Nesta breve circunstância podese ilustrar o funcionamento da percepção identificando os três elementos já apresentados. Primeiramente, a obra de arte em si seria o percepto, já o percipuum seria o conjunto de aspectos emanados da obra, e por fim, o aspecto percebido pelo indivíduo que denomina-se julgamento perceptivo, o qual é produzido pela mente através de um processo inferencial da percepção.

Desta forma, relaciona-se os elementos da tríade de percepção formulada por Peirce, a alguns conceitos fundamentais de sua arquitetura filosófica. Em síntese relaciona-se o percepto ao objeto dinâmico, o percipuum ao objeto imediato e o julgamento perceptivo às inferências abdutivas. 
A seguir apresenta-se a relação do julgamento perceptivo com os elementos da segunda tricotomia dos signos, o ícone, o índice e o símbolo. Ao agir como signo, o julgamento perceptivo apresenta três perspectivas equivalentes aos tipos sígnicos de Peirce: a icônica, a indicial e a simbólica. Santaella (2012b, p. 128) comenta que "nessa medida, o ingrediente icônico é justamente aquilo que dá suporte ao processo perceptivo, funcionando como substrato da ilusão, subjacente a toda percepção, de que o objeto, tal como percebido, é o próprio objeto". Na visão de Granja (2005), a mediação icônica nos faz reconhecer tanto a forma geral dos objetos (a forma circular, a forma de uma cadeira), como a forma particular do objeto imediato que se apresenta à percepção. $\mathrm{A}$ junção entre o geral da semelhança icônica ao particular do objeto percebido corresponde justamente à dimensão indicial do julgamento perceptivo. Na sua dimensão simbólica ou de generalidade, o juízo de percepção é falível, e pode ser reavaliado a partir de experiências futuras.

Em geral, a representação de um objeto é complexa, que consiste em várias funções icônicas, indexais e simbólicas, as quais atuam na formação do julgamento perceptivo. Os ingredientes icônicos contribuem ao apresentar características gerais que permitem a identificação de traços essenciais à formação mental do percipuum. Em outro aspecto uma conexão indicial também é importante para fixar a referência, através dos indícios que se aproximam numa relação efetiva de seu objeto, afinal o índice é um indicador do seu objeto. A dimensão simbólica opera no terceiro nível do interpretante, onde através das características e indícios relacionados é formulado pensamento na mente, onde este pensamento é um símbolo. Dessa forma o julgamento perceptivo produz o que é percebido mentalmente.

Conforme destacado por Rego, Pessoa e Gala (2015, p. 105), Peirce não desenvolveu um texto que sistematizasse sua teoria da percepção, entretanto alguns intérpretes de sua obra organizaram essas ideias apresentando uma teoria muito rica. Desta forma, os elementos desta teoria estão calcados em sua arquitetura filosófica, onde os conceitos do processo perceptivo estão intimamente relacionados a todo trabalho desenvolvido no decorrer de suas pesquisas.

\subsection{A percepção e o desenvolvimento de interfaces Web}

O objetivo desta seção é encontrar elementos da teoria da percepção de Peirce que possam beneficiar o desenvolvimento de interfaces Web, tendo em vista o processo de recuperação da in- formação. A percepção humana é um fator essencial a ser considerado no projeto de interfaces digitais, Andersen (2001) salienta a importância de estudos focados na interação entre as máquinas e os seres humanos, ele destaca o núcleo da semiótica na realização de estudos que discutam as representações e também a forma como os usuários interpretam essas representações. A seguir são elencadas algumas análises que consideram a percepção e a semiótica em diversas vertentes, e que colaboram para o desenvolvimento de interfaces digitais.

A relação entre a percepção humana e a organização do conhecimento foi destacada por Barat (2005), nessa pesquisa apresenta-se alguns aspectos referentes à teoria da percepção e à teoria linguística. $O$ autor discute as vantagens das teorias, na teoria perceptual ele elenca três itens: a representação homogênea da primeira percepção, a visualização clara e lógica e os padrões de alto nível de processamento de dados e recuperação de informação. Na teoria linguística, é diagnosticado que ela é comum, conhecida e os símbolos são compreensíveis, além de descrever que os símbolos se comunicam diretamente e instantaneamente. A partir desses conceitos são listados também alguns pontos sobre percepção visual e recuperação de informação. Em suas conclusões reafirma a importância da compreensão da percepção no processo de gestão da informação. A apresentação do estudo fortalece a ideia de analisar a percepção como fator essencial no desenvolvimento de elementos que visam a melhor compreensão humana.

No que diz respeito aos estudos sobre interfaces digitais relacionadas à semiótica, a área de Engenharia Semiótica (ES) é apresentada por Souza (2005) como a teoria semiótica da área de IHC (Interação Humano Computador). Neste sentido a autora discute em seu artigo a ES como suporte teórico no desenvolvimento de interfaces com artefatos interativos que realmente possam trazer novas perspectivas e possibilidades de design em IHC. A ES trata a IHC como um tipo específico de comunicação mediada por computador, considerando a troca de mensagens dos usuários com os designers de sistemas computacionais, essas mensagens são o representamen (ou seja, o sinal perceptível que representa a mensagem) em que o próprio sistema informa aos usuários como se comunicar com ele. Em favor da engenharia semiótica defende-se que ela pode ajudar os designers a compartilhar responsabilidades com os usuários no processo comunicativo.

Também seguindo a vertente da engenharia semiótica, Vandi (2007) avaliou a forma como a semiótica possibilita analisar a ação prática dos 
usuários reavaliando o uso de metáforas em interfaces gráficas, o autor considera metáforas os itens destinados a dar ao usuário um contexto familiar para agir: um escritório com lixeiras, pastas e arquivos. No artigo foram exemplificadas algumas interfaces computacionais que contém tais itens, sendo diagnosticado que a tarefa de um bom projetista é usar esses elementos para estimular a aprendizagem, e a fácil criação de hábitos de ação. Os hábitos de ação iniciam-se através da percepção, para Peirce (1994, CP 5.212) "os elementos de todo conceito entram no pensamento lógico pelos portões da percepção", ou seja, toda informação deve entrar pelas portas da percepção, apresentando-se em forma de uma ideia ou hábito mental compartilhado numa comunidade.

Islam (2013) realizou uma revisão de literatura que abordou a percepção semiótica em interfaces de usuários no que diz respeito ao projeto e avaliação de usabilidade, foram selecionados 65 artigos que identificaram alguns desafios da área. No artigo, afirma-se a necessidade de realização de mais pesquisas ligadas ao tema com o intuito de melhorar a qualidade das publicações. O autor revela que apenas $18 \%$ dos artigos apresentaram o design de interface ou princípios de avaliação de usabilidade, cerca de $51 \%$ estavam relacionados a percepção semiótica, apresentando teorias, métodos e estruturas. Após uma verificação criteriosa nos estudos, o autor conclui que a revisão mostrou a importância da semiótica nas pesquisas interface do usuário, além disso sugere-se direcionar novos estudos à algumas lacunas de pesquisa identificadas, entre elas a percepção semiótica na avaliação da usabilidade.

Embora não tenha tratado especificamente sobre interfaces digitais, Gambarato (2013) discutiu a semiótica de Peirce no processo de design, em especial o conceito de abdução. A autora apresentou o potencial comunicativo dos signos com uma breve análise da teoria da percepção explicando a importância do conceito de abdução criado por Peirce. No artigo, é destacada a capacidade de representação por meio dos signos, e por fim conclui que o processo criativo no design tem o objetivo de associar signos e gerar novos interpretantes. Esse estudo apresentou-se interessante no que diz respeito à visão da teoria da percepção em processos comunicativos, visto que as interfaces também podem ser consideradas parte do processo comunicacional.

Magnani e Bardone (2006) discorreram sobre a relação do conceito de abdução e o projeto para interfaces web. No artigo apresentou-se a importância de três dimensões para as inferências ab- dutivas: a visual, a espacial e a emocional. A dimensão visual é exemplificada através do uso de cores, tamanhos e formatos. Já a dimensão espacial diz respeito a disposição dos elementos na interface, proporcionando a realização de tarefas específicas. No caso da dimensão emocional consideram-se aspectos de alertas aos usuários a partir de caixas de diálogo, sons e cores com significados de advertência e sucesso por exemplo. Os autores consideram a interface como fundamental na compreensão da interação humanocomputador, e que esta interação pode ser melhor compreendida através do modelo inferencial. Por conta da possibilidade da interface fornecer pistas a partir das quais os usuários possam ter uma meIhor percepção do ambiente, os autores consideram o processo como genuinamente abdutivo.

No que diz respeito à navegação em interfaces digitais web, Santaella (2004) identifica perfis relacionados às três categorias gerais de Peirce. Os tipos de raciocínio, abdutivo, indutivo e dedutivo, determinam diferentes percursos de leitura para três tipos de leitores (ou internautas): o errante, o detetive e o previdente. Neste cenário, o internauta errante é considerado o leitor novato, que por meio do raciocínio abdutivo navega aleatoriamente através da possibilidades à ele apresentadas. A indução é própria do internauta detetive, que está em processo de aprendizado, já que navega seguindo indícios (pistas) em busca da informação que necessita. Por sua vez, o internauta previdente é capaz de prever o resultado de suas ações na pesquisa, pois já passou pelo processo de aprendizagem e aplica o raciocínio dedutivo para avançar nos ambientes informacionais. Embora esses estilos sejam diferentes, existem pontos em comum, pois independente do itinerário os internautas recebem estímulos que despertam a percepção e a cognição. Dessa forma é identificado o papel fundamental da percepção no processo de navegação, onde o fatores sensoriais provocam imediatas reações perceptivas em sincronia com operações mentais.

Os estudos elencados acima, apresentaram diversos aspectos da perspectiva semiótica, englobando a teoria da percepção de Peirce, sugerindo que seu contribuição está voltada ao desenvolvimento de interfaces digitais. Contudo, verifica-se a necessidade de aprofundamento nos estudos experimentais relativos à percepção, sendo a semiótica de Peirce certamente um caminho teórico a ser percorrido.

\section{Considerações finais}

Estudar a percepção e decifrar como ela age na formação do pensamento, é um ganho impor- 
tante para o entendimento da cognição em qualquer área disciplinar. Retornando a questão que norteou este trabalho, quais aspectos da semiótica peirceana contribuem para compreensão do processo de percepção humana? Foi possível relacionar os diversos fatores da arquitetura filosófica peirceana que se destacam no processo perceptivo. A proposta triádica, composta pelo percepto, o percipuum e o julgamento perceptivo, se conectou com as categorias universais, aos objetos do signo e ao conceito de abdução.

A partir da apresentação das teorias observou-se as diversas abordagens sobre o tema, além de elencar algumas aplicações na área da Ciência da Informação que utilizam essas teorias como base para suas pesquisas. Com a revisão conceitual sobre a teoria da percepção de Peirce concluiu-se que seus conceitos fornecem subsídios para análise de diversos domínios do conhecimento, e proporciona um melhor entendimento do processo de percepção, substituindo uma relação diádica cartesiana de sujeito-objeto, para uma relação triádica do processo de percepção.

Nas diferentes áreas observadas foi possível identificar os componentes da tríade perceptual, isto é, entende-se que existem elementos a serem percebidos (percepto), como esses elementos se apresentam ao julgamento de percepção (percipuum), e como tudo isto é imediatamente interpretado, o julgamento de percepção. Além dessa apresentação dos aspectos dos signos, outra vertente destacada diz respeito ao perfil dos internautas que utilizam interfaces Web, os aspectos perceptivos e cognitivos são influenciados por diferentes itinerários de navegação que podem ser distinguidos pelos tipos de raciocínio, abdutivo, indutivo e dedutivo. Dessa forma, uma sugestão de trabalhos futuros seria aperfeiçoar os processos cognitivos através do estudo da percepção, isto é, agir sobre cada elemento identificado no processo. Conforme destacado por Jorge, Rezende e Wartha (2013), a Teoria da Percepção poderia sustentar eficientemente 0 desenvolvimento da habilidade viso espacial, ou a questão da carga cognitiva sobre conceitos que demandam altas habilidades viso espaciais por meio do uso de ferramentas de visualização.

O desenvolvimento de interfaces digitais deveria levar em conta as fases do processo de percepção elencados por Peirce, além, é claro, dos tipos de mediação (icônica, indicial e simbólica) que se apresentam na interação homem-computador. Sem estes conhecimentos, as interfaces seriam apenas um mecanismo artificial e pouco eficiente de possibilitar a interação humana, o que, ao fim e ao cabo, interfere negativamente na aquisição de conhecimento e na fluência no uso do sistema.

\section{Referencias}

Alexandre, D. S.; Tavares, J. M. R. S. (2007). Factores da percepção visual humana na visualização de dados. // APMTAC. http://hdl.handle.net/10216/357. (2015-11-10).

Almeida, C. C. (2009). Peirce e a organização da informação: contribuições teóricas da semiótica e do pragmatismo. Marília: Universidade Estadual Paulista (UNESP), 2009. Tese de Doutorado.

Andersen, P. B. (2001). What semiotics can and cannot do for HCl. // Knowledge-Based Systems. 14:8, 419-424.

Andrade, S. M. et al (2012). Construção e evidências psicométricas de uma escala de avaliação da percepção visual. // Psicologia: Reflexão e Crítica. 25, 21-29.

Barat, A. H. (2005). The relationship between human perception and knowledge organization. // La dimensió humana de l'organització del coneixement. Facultat de Biblioteconomia i Documentació. p. 286-295.

Barros, C. M. de; CAFÉ, L. M. A. (2012). Estudos da semiótica na Ciência da Informação: relatos de interdisciplinaridades. // Perspectivas em Ciência da Informação. 17:3, 1833.

Chaui, M. (2000). Convite à filosofia. 7. ed. São Paulo: Ática, 2000.

Correia, M. F. P. V. (2001). Técnicas computacionais na percepção visual do movimento. Porto: Universidade Fernando Pessoa, 2001. Tese de Doutorado.

Frankenthal, E. S. (2004). O pragmatismo na abdução e na percepção. // Cognitio-Estudos: Revista Eletrônica de Filosofia. 1, 1-9.

Gambarato, R. R. (2004). Peircean semiotics in the context of design praxis: Abduction and perception in dialogue. // Sign Systems Studies. 41:4, 424-432.

Granja, C. E. S. C. (2005). Música, conhecimento e educação: harmonizando os saberes na escola. São Paulo: Universidade de São Paulo (USP), 2005. Dissertação de Mestrado.

Hausman, C. R. (2006). A Semiótica de Peirce aplicada à percepção: O papel dos objetos dinâmicos e dos perceptos na interpretação perceptiva. // Cognitio. 7:2, 231-246.

Ibri, I. A. (2006). The heuristic exclusivity of abduction in Peirce's philosophy. // Leo, R. F.; Marietti, S. (eds.). Semiotics and Philosophy in C. S. Peirce. Cambridge: Cambridge Scholars Press.

Islam, M. N. (2013). A systematic literature review of semiotics perception in user interfaces. // Journal of Systems and Information Technology. 15, 45-77.

Jorge, A. M. G. ; Rezende, D. B.; Wartha, E. J. (2013). Visualização, semiótica e teoria da percepção. // Tríade. 1:1, 149-166.

Loomis, J. M. (2003). Percepção visual do espaço: fenomenologia e função. // Arquivos Brasileiros de Oftalmologia. 66:5, 26-29.

Magnani, L. Bardone, E. (2006). Abduction and Web Interface Design. // Mueller, G. C. (org.). Encyclopedia of Human Computer Interaction. Liverpool: IGI.

Matsunaga, C. (2015). Entre ver e interpretar: o papel fundamental do design. // Anais $7^{\circ}$ Congresso Internacional de Design da Informação. 797-808. http://www.proceedings.blucher.com.br/article-details/entre-ver-e-interpretar-o-papel-fundamental-do-design-20260 (2016-07-20).

Moraes, J. A.; Pereira, P. H. A. O.; Pantaleão, N. C. A. (2012). Percepção direta: contribuições do pragmatismo peirciano para a abordagem ecológica. // Revista Eletrônica de Filosofia. 9, 195-204.

Mucelin, C. A.; Bellini, M. (2008). Estudo da percepção em ecossistema urbano: uma contribuição para a educação, 
planejamento e gestão ambiental. // Revista Brasileira de Estudos Pedagógicos. 89:221, 119-144.

Nóbrega, T. P. (2008). Corpo, percepção e conhecimento em Merleau-Ponty. // Estudos de Psicologia. 13:2, 141-148.

Nöth, W. (2003). Panorama da semiótica de Platão a Peirce. 4. ed. São Paulo: Annablume, 2003

Peirce, C. S. (2005). Semiótica. 4. ed. São Paulo: Perspectiva, 2005.

Peirce, C. S. (1994 The electronic edition of the collected papers of Charles Sanders Peirce. Vols. I-VI. // Hartshorne, C.; Weiss, P. (eds.). Cambridge: Harvard University Press.

Rego, J. M. R.; Pessoa, G. H. R.; Gala, A. C. O. S. (2015). A Percepção em três registros: Russell, Peirce e Caeiro. // Revista Eletrônica de Filosofia. 12, 98-116.

Rocha, L. B. (2002). Fenomenologia, semiótica e geografia da percepção:alternativas para analisar o espaço geográfico. // Revista da Casa da Geografia de Sobral. 4:1, 67-79.

Romanini, A. V. (2006). Semiótica minuta: especulações sobre a gramática dos signos e da comunicação a partir da obra de Charles S. Peirce. São Paulo: Escola de Comunicações e Artes da Universidade de São Paulo (USP), 2006. Tese de Doutorado.

Santaella, L. (2015). Semiótica aplicada. São Paulo: Cengage Learning, 2015.

Santaella, L (2012a). O que é semiótica. São Paulo: Editora Brasiliense, 2012a.

Santaella, L. (2012b). Percepção: fenomenologia, ecologia, semiótica. São Paulo: Cengage Learning, 2012b.
Santaella, L. (2004) Navegar no ciberespaço: o perfil cognitivo do leitor imersivo. São Paulo: Editora Paulus, 2004.

Santaella, L. (1998) A percepção: uma teoria semiótica. 2. ed. São Paulo: Experimento, 1998.

Santaella, Lucia. A teoria geral dos signos: semiose e autogeração. São Paulo: Ática, 1995.

Santos, N. A. (2003). Tópicos em percepção e processamento visual da forma: acuidade visual versus sensibilidade ao contraste. // Estudos e Pesquisas em Psicologia. 3:1, 61-71.

Schultz, S. (2012). A análise gödeliana do conceito de percepção. // Doispontos. 9:2, 135-150.

Sousa, H. M. R. C. (2009). Percepção humana na visualização de informação crítica. Porto: Universidade do Porto, 2009. Dissertação de Mestrado.

Souza, C. S. (2005). Semiotic engineering: bringing designers and users together at interaction time. // Interacting with Computers. 17:3, 317-341.

Vandi, C. (2007). Beyond metaphors and icons: towards a perception-action model for graphic user interfaces. // Anais 9th World Congress of IASS/AIS. http://www2.uiah.fi/sefun/DSIU_papers/DSIU_Vandi_Beyond\%20metaphors\%20and\%20icons.pdf (2016-07-20).

Enviado: 2017-03-31. Segunda versión: 2017-09-06. Aceptado: 2017-09-15. 